\title{
Multilevel Structure and Properties of Metals and Polymers within the Unified Model of Chemical
}

\author{
Oleg Sirotkin and Rostislav Sirotkin ${ }^{*}$ \\ Department of Materials Science and Engineering, Kazan State Power Engineering University, Kazan 420066, Russia
}

\begin{abstract}
The object of the work is to examine metallic and polymer materials from a single point of view in terms of their structure. As a result, a unified classification of levels of structural organization of metallic and polymer materials, based on the unified model of chemical bond, was proposed. The unity of different materials' nature at chemical structural level is shown. The effect of the type of chemical bond on subsequent levels of materials' structural organization, difference in properties and contribution of specific levels to some properties of materials are shown.
\end{abstract}

Key words: Metals, polymers, chemical bond, structure, property.

\section{Introduction}

Among various natural and synthetic materials, materials based on metals (mostly alloys), as well as organic and inorganic (such as glasses, ceramics) polymers, are of special interest for materials science. Due to huge practical importance, it is these groups of materials that are best studied including their structural characteristics [1, 2]. In metallography materials structure is traditionally divided into four levels [3]: macrostructure $\left(\sim 10^{-1} \mathrm{~m}\right)$, microstructure $\left(\sim 10^{-4} \mathrm{~m}\right)$, substructure $\left(\sim 10^{-7} \mathrm{~m}\right)$ and fine structure (submicrostructure) $\quad\left(\sim 10^{-9} \mathrm{~m}\right)$. Contemporary achievements of structural chemistry and physics, as well as mechanics, have led to the need to develop a unified approach to structural hierarchy: macrostructure (fractures, dendrites and polyhedral structures, grains and their orientation, $\sim 10^{-3} \sim 10^{-1}$ $\mathrm{m}$ ); mesostructure (structure within grains, dislocations and dislocation ensembles, disclinations, polygons, $\sim 10^{-7} \sim 10^{-3} \mathrm{~m}$ ); microstructure (X-ray structure, formed by point defects, crystal lattices, $\sim 10^{-10} \sim 10^{-7} \mathrm{~m}$ ), including apparently nanostructures.

${ }^{*}$ Corresponding author: Rostislav Sirotkin, Ph.D., associate professor of materials science, research fields: materials structure, structure properties relations and chemical bond.

\section{Results and Discussion}

These classifications are traditionally based on systematization of metals' structures (with no reference to structures formed by polymers - one of the most important class of materials), while the location of nanostructures in these classifications is not clearly specified. Therefore the corrected universal classification of levels of structural organization for metallic and nonmetallic materials can be presented as follows (Table 1) [4-6]: microstructure (including 3 sublevels: electron-nuclear, molecular (both form fine structure) and nanostructure), mesostructure and macrostructure.

Dimensional characteristics of these levels for metals and polymers, as well as the elements that these levels composed of, are given in Table 1. This classification is also applicable to ceramic materials, as their microstructure (including the electron-nuclear one) is similar to the one in polymers (primarily covalent bonding of atomic cores) and metals (polycrystals). Main conclusions, which can be made while analyzing Table 1, are as follows:

Electron-nuclear microstructure (1a) is common for any kind of metallic and nonmetallic material, as any material is formed by chemical elements (atomic cores) tied by chemical bonds; 
Table 1 Classification of main levels of structural organization of metallic and polymer materials.

\begin{tabular}{|c|c|c|c|}
\hline \multicolumn{2}{|c|}{$\begin{array}{l}\text { Structural levels and their } \\
\text { dimensional range }\end{array}$} & Structural elements in metals & Structural elements in polymers \\
\hline \multicolumn{2}{|c|}{1} & 2 & 3 \\
\hline \multicolumn{4}{|c|}{ 1. Microstructure: } \\
\hline \multirow{2}{*}{ fine } & $\begin{array}{l}\text { 1a) electron-nuclear } \\
\sim 1-5 \AA\left(1-5 \cdot 10^{-10} \mathrm{~m}\right)\end{array}$ & \multicolumn{2}{|c|}{$\begin{array}{l}\text { Atomic cores and collectivized electrons, which provide chemical bonding (predominantly metallic } \\
\text { bond in metals and mainly covalent bond in polymers); Point defects: vacancies, etc. } \\
(0,0001-0,0005 \mathrm{mkm})\end{array}$} \\
\hline & $\begin{array}{l}\text { 1b) molecular } \\
\text { 5-10 } \\
\left(0.5-1 \times 10^{-9} \mathrm{~m}\right) \\
\end{array}$ & $\begin{array}{l}\text { Primary "aggregates" of atomic cores, in metals there } \\
\text { are no molecules }\end{array}$ & $\begin{array}{l}\text { Fragments of macromolecules (atomic } \\
\text { groups) tied by van der Waals (vdW) and } \\
\text { hydrogen bonds }(0.0005-0.001 \mathrm{mkm})\end{array}$ \\
\hline \multicolumn{2}{|c|}{$\begin{array}{l}\text { 1c) nanostructure } \\
\sim 10-10000 \AA \\
\left(10^{-9}-10^{-6} \mathrm{~m}\right)\end{array}$} & $\begin{array}{l}\text { Nanoparticles }(0.001-0.1 \mathrm{mkm}) \text { and interfaces; } \\
\text { Fragments, blocks, polygons }(0.1-1 \mathrm{mkm}) \text { и } \\
\text { coherent-scattering region }(0.001-0.01 \mathrm{mkm}) \text {; Line } \\
\text { defects: dislocations and disclinations }(0.1-1 \mathrm{mkm})\end{array}$ & $\begin{array}{l}\text { Macro (oligo-) molecules tied by intra- and } \\
\text { intermolecular vdW and hydrogen } \\
\text { interactions; SMS }{ }^{*} \text { : nanoparticles and } \\
\text { interfaces; crystallites, lamellae; Line defects }\end{array}$ \\
\hline \multicolumn{2}{|c|}{$\begin{array}{l}\text { 2. Mesostructure } \\
\sim 10^{4}-10^{7} \AA \\
\left(10^{-6}-10^{-3} \mathrm{~m}\right)\end{array}$} & $\begin{array}{l}\text { Subgrains (1-100 mkm) and subgrain boundaries; } \\
\text { Grains (100-1000 mkm) and boundaries between } \\
\text { them; Planar defects (dislocation assemblies) }\end{array}$ & $\begin{array}{l}\text { SMS: small axialites, hedrites and spherulites } \\
\text { up to several dozens of mkm; Planar and } \\
\text { small bulk defects (voids, etc.) }\end{array}$ \\
\hline \multicolumn{2}{|c|}{$\begin{array}{l}\text { 3. Macrostructure } \\
\sim 10^{7}-10^{9} \AA\left(10^{-3}-10^{-1} \mathrm{~m}\right)\end{array}$} & $\begin{array}{l}\text { Structures formed by grains (fibres, dendrites, etc.) } \\
\text { and interfaces; Bulk defects (cavities, cracks, etc.) }\end{array}$ & $\begin{array}{l}\text { SMS: large supramolecular formations in the } \\
\text { form of large axialites, hedrites and } \\
\text { spherulites (over several dozens of mkm); } \\
\text { Large bulk defects (cracks, etc.) }\end{array}$ \\
\hline
\end{tabular}

*SMS - Supramolecular structures in polymer materials.

Table 2 Specifics of structure and properties of substances depending on dominant chemical bond type.

\begin{tabular}{|c|c|c|}
\hline Characteristic & $\begin{array}{ll}\text { Metallic Compounds } \\
\text { berthollides) }\end{array}$ & $\begin{array}{l}\text { Covalent - Polymer Compounds } \\
\text { (molecular, daltonides) }\end{array}$ \\
\hline 1 & 2 & 3 \\
\hline I. Composition & Homo- and heteronuclear & Homo- and heteronuclear \\
\hline $\begin{array}{l}\text { II. Specificity of chemical bond, } \\
\text { determined by the character of } \\
\text { collectivized electrons' distribution } \\
\text { between atomic nuclei }\end{array}$ & $\begin{array}{l}\text { a) DEC } \rightarrow 100 \% \text {, } \\
\mathrm{C}_{\mathrm{M}}>>\mathrm{C}_{\mathrm{C}}\left(\mathrm{C}_{\mathrm{I}}\right) \\
\text { b) Collectivized electrons are minimally } \\
\text { localized between nuclei; } \\
\text { c) Electronic density, } \delta \text {, is minimal between the } \\
\text { nuclei and uniformly distributed }\left(\delta^{\prime}=\delta^{\prime \prime}\right) \\
\delta / \delta^{\prime \prime}\end{array}$ & $\begin{array}{l}\text { a) } \mathrm{DEC} \rightarrow 50 \%, \mathrm{C}_{\mathrm{C}}>>\mathrm{C}_{\mathrm{M}} \text { and } \mathrm{C}_{\mathrm{I}} \text {; } \\
\text { b) Collectivized electrons are localized } \\
\text { between nuclei; } \\
\text { c) Electronic density, } \delta \text {, is maximum between } \\
\text { nuclei (normally it is shown as a dash that } \\
\text { connects nuclei) }\end{array}$ \\
\hline III. Structure & $\begin{array}{l}\oplus \oplus^{-} \oplus^{-} \oplus^{-} \oplus^{-} \oplus{ }^{-} \oplus \\
\oplus^{-} \oplus_{(-)}^{\oplus} \oplus \mathbf{M g}^{+} \longrightarrow \oplus \\
\mathrm{E}_{\mathrm{Me}}^{\mathrm{n}} \cdots \mathrm{e} \cdots \mathrm{E}_{\mathrm{Me}}^{\mathrm{n}+}\end{array}$ & 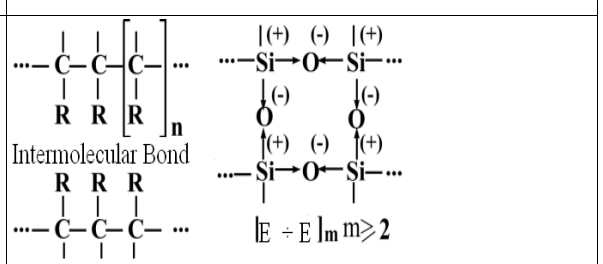 \\
\hline IV. Characteristic properties & $\begin{array}{l}\text { 1. Electric conductivity } \\
\text { 2. Ductility } \\
\text { 3. High density } \\
\text { 4. Metallic luster and opaqueness }\end{array}$ & $\begin{array}{l}\text { 1. Dielectric properties } \\
\text { 2. Elasticity } \\
\text { 3. Low density } \\
\text { 4. Transparency }\end{array}$ \\
\hline V. Aggregate state & Solid substance & Solid or liquid substance (solution, melt) \\
\hline
\end{tabular}

The differences in structure of subsequent levels (and, consequently, properties) are determined by specificity of chemical bond (primarily covalent, metallic or ionic) and manifest themselves starting from molecular- and nano-sublevels of metallic and nonmetallic materials and then on meso- and 
macrolevels.

These conclusions are summarized in more detail in Table 2.

The DEC (Degree of electrons collectivization) is determined as the number of atomic cores (n) within a chemical compound's structure localizing collectivized electrons, which provide chemical bonding [7-11]:

$$
\mathrm{DEC}=100-100 / \mathrm{n}
$$

while covalent character $\left(\mathrm{C}_{C}\right)$, metallic character $\left(\mathrm{C}_{\mathrm{M}}\right)$ and ionic character $\left(\mathrm{C}_{\mathrm{I}}\right)$ of chemical bond within its unified model (Eq. (2)), which unites the three types, are calculated according to the procedure [7, 12].

$$
\psi=\mathrm{c}_{1} \psi_{\mathrm{COV}}+\mathrm{c}_{2} \psi_{\mathrm{MET}}+\mathrm{c}_{3} \psi_{\mathrm{ION}}
$$

where, $\Psi$ is the wave function; $\mathrm{C}_{1}, \mathrm{C}_{2}$ and $\mathrm{C}_{3}$ are coefficients, which, respectively, determine the shares of covalent, metallic and ionic components of chemical bond and are equal to 1 or $100 \%$, in total .

As a result, difference in $\mathrm{C}_{C} / \mathrm{C}_{\mathrm{M}} / \mathrm{C}_{\mathrm{I}}$ ratio in metals and polymers leads to qualitative differences in their (1b) sublevel of microstructure (nonmolecular and molecular ones, respectively). This, in turn, leads to fundamental difference in their properties (conductor/dielectric, plasticity/elasticity, high density/low density, etc.). It has to be pointed out that in polymers, unlike metals, the presence of macromolecules bonded by relatively weak van-der-Waals physical forces sets conditions for their existence in two states: liquid (solution or melt) and solid (Table 2). It is for this reason processing of polymers occurs at temperatures approximately ten times lower than processing of metals.

The importance of creation of a universal classification of structural levels for different materials stems both from theoretical needs to concretize the main object and basic notion of materials science - material and from practical reasons. The latter, in particular, is due to the fact that at the moment special emphasis is laid on development of approaches to forming and regulating materials' structure at fine and nanolevels (e.g., upon formation of nanomaterials), which should lead to acquisition by the materials of new properties essential for practical use in modern products and structures.

In addition, the materials ultimate properties are determined by the cumulative contribution of each of the above levels or sub-levels of structural organization. As a result, in general, any property (physical, mechanical, chemical, etc.) of metallic or nonmetallic material can be determined as a sum of contributions of all structural levels [4]:

$$
\mathrm{MP}=\mathrm{f}\left(\Sigma\left(\mathrm{k}_{\mathrm{i}} \cdot \mathrm{MP}_{\mathrm{i}}\right)\right)
$$

where, MP - material's property; $\mathrm{MP}_{\mathrm{i}}$ - material's property determined by a certain structural level according to Table $1 ; \mathrm{k}_{\mathrm{i}}$ - coefficient, which takes into account contribution of a given structural level of material to a certain (physical, mechanical, chemical, etc.) property (Table 1).

Despite the fact that all structural levels contribute to properties of any material, as a rule, for many properties one can point out a level of structural organization whose contribution to a certain property is dominant. For example, electron-nuclear structure determines such characteristics of metals as plasticity (corresponding to diffusion and self-diffusion mechanisms), stiffness (characterized by Young's modulus), electrical conductivity, resistance to corrosion; nanostructure determines crowdion and dislocation plasticity. Magnetic properties are determined by the structural elements (magnetic domains), whose size corresponds to nano- and mesostructure, while brittleness - by the elements of nano-, meso- (dislocations and their ensembles) and macrostructure (cracks). Similar correlations can be drawn for polymer materials: ageing due to macromolecules' destruction and cross-linking is determined by characteristics of electron-nuclear structure; intermolecular bonds of molecular structure have an effect on most physical and mechanical 
properties of polymers, for example, glass transition temperature, softening temperature and melting point, solubility, melt viscosity, crystallinity, strength, yield, etc. It is also known that many important from practical point of view polymers' characteristics, such as yield stress [13], yield strain [14], tensile strength and relaxation transitions [15-17] are determined by the elements of supramolecular structure, which form nano-, meso- and macrostructure.

\section{Conclusions}

Traditional classifications of levels of materials' structural organization are normally based on systematization of metals' structures. In the present work, metallic and polymer materials were examined from a single point of view in terms of their structure. As a result, a unified classification of levels of structural organization of metallic and polymer materials, based on the unified model of chemical bond, was proposed. Application of the unified model of chemical bond allowed to show the effect of the type of chemical bond on subsequent levels of materials' structural organization, difference in properties and contribution of specific levels to some properties of materials.

\section{References}

[1] Sirotkin, O. S. and Sirotkin, R. O. 2006. "Modelling of Structure and Properties of Metallic and Nonmetallic Materials within the Paradigm of their Multilevel Organization." All-Russia Conference of Materials Scientists of Russia “Advanced technologies of materials' processing", Ul'yanovsk, 7.

[2] Sirotkin, R. O. and Sirotkin, O. S. 2006. "Structure of Metallic and Nonmetallic Materials.” Kazan, KSPEU.

[3] Tushinsky, L. I. 2004. "Structural Theory of Materials' Structural Strength.” Novosibursk, NSTU.

[4] Sirotkin, R. O. 2007. "Electron-Nuclear, Molecular and
Supramolecular Structure of Polymer Materials and their Physical and Chemical Properties ('Composition - Bond Type - Structure - Properties' in Polymers and Metals).” Kazan, KSPEU.

[5] Sirotkin, R. O. 2008. "Unity and Difference of Structure and Properties of Polymer and Metallic Materials." Technology of Metals 7: 38.

[6] Sirotkin, O. S., Sirotkin, R. O. 2010. Principles of Theoretical Materials Science. Kazan, KSPEU.

[7] Sirotkin, O. S. 2003. Principles of Unified Chemistry. Kazan, Fen.

[8] Sirotkin, O. S. Principles of Innovative Materials Science. Moscow: Infra-M.

[9] Sirotkin, O. S. Principles of Materials Science. Moscow, KNORUS.

[10] Sirotkin, O.S. Principles of Materials Science. Moscow, KNORUS.

[11] Sirotkin, O. S. and Sirotkin, R. O. 2011. "Unified Model of Chemical Bonds and System, which Unites them, as Fundamental Basis for New Stage of Development of A.M. Butlerov's Theory Chemical Structure of Substance." In Proceeding of International Congress on Organic Chemistry. Kazan, 73.

[12] Sirotkin, O. S., Sirotkin, R. O. and Trubacheva, A. M. 2005. "On the Necessity and Procedure of Taking into Account the Metallic Component of a Heteronuclear Bond." Russian Journal of Inorganic Chemistry 50 (1): 67.

[13] Sirotkin, R. O. and Brooks, N. W. 2001. "The Effects of Morphology on the Yield Behaviour of Polyethylene Copolymers." Polymer 42: 3791.

[14] Sirotkin, R. O. 2005. "The Effect of Supramolecular Structure on the Yield Strain of Ethylene Copolymers Crystallized from Solution." Polymer Science A 47 (3): 283.

[15] Sirotkin, R. O. and Brooks, N. W. 2001. "The Dynamic Mechanical Relaxation Behaviour of Polyethylene Copolymers Cast from Solution.” Polymer 42: 9801.

[16] Sirotkin, R. O. and Sirotkin, O. S. 2005. "Specifics of Relaxation Transitions and Deformation in Ethylene-1-Hexene Copolymers Crystallized from Solution.” Polymer Science B 47 (7-8): 223.

[17] Sirotkin, R. O. 2006. "The Effect of Supramolecular Structure on Deformation and Relaxation Transitions in Ethylene-1-Hexene Copolymers Crystallised from Solution.” Polymer Science B 48 (3-4): 65. 